Cómo citar este trabajo: Álvarez Otero, J., \& de Lázaro y Torres, M. ${ }^{a}$ L. (2019). Las infraestructuras de datos espaciales: un reto y una oportunidad en la docencia de la Geografía. Boletín de la Asociación de Geógrafos Españoles, 82, 2787, 1-32. http://dx.doi.org/10.21138/bage.2787

\title{
Las infraestructuras de datos espaciales: un reto y una oportunidad en la docencia de la Geografía
}

Spatial data infrastructures: a challenge and an opportunity for teaching geography

\author{
Javier Álvarez Otero \\ javier.alvarez.otero@ucm.es \\ Doctorando \\ Universidad Complutense de Madrid (España) \\ María Luisa de Lázaro y Torres \\ mllazaro@geo.uned.es \\ Universidad Nacional de Educación a Distancia (UNED) (España)
}

\section{Resumen}

La creciente importancia de los datos como materia prima exige al docente prestar una mayor atención a los mismos. Los servicios y visores de las Infraestructuras de Datos Espaciales (IDE), mantenidos por los organismos públicos responsables de ellos, ofrecen una gran riqueza de datos geográficamente referenciados o geodatos, lo que constituye un excelente recurso docente. Esos datos son libres, abiertos, ofrecen la ventaja de su calidad, interoperabilidad, transparencia, reutilización, facilidad de acceso y actualización, a veces en tiempo real, y con ellos, el estudiante puede alcanzar una comprensión del territorio más precisa. Se ha valorado la utilidad de su empleo a través de la técnica Delphi. Con ella, se ha reunido una gran riqueza de información aportada por expertos en IDE y usuarios (investigadores, técnicos y docentes), cuyo análisis ha permitido concluir que, a pesar del interés de los datos existentes en las IDE para la comprensión del territorio, existen barreras todavía que frenan su empleo, principalmente derivadas de su complejidad. 
Palabras clave: Geografía; aprendizaje basado en el territorio; Infraestructuras de Datos Espaciales (IDE); Técnica Delphi; geodatos.

\begin{abstract}
The increasing importance of data as raw material means teachers should pay them more attention. The services and viewers on the Spatial Data Infrastructures (SDI), maintained by the public bodies responsible for them, offer a wealth of geographically referenced data (geodata), which constitutes an excellent teaching resource. These data are free as well as open. They offer the advantage of quality, interoperability, transparency, reuse, ease of access and updating, sometimes in real time. The student can achieve a more accurate understanding of the territory because of the data. The Delphi technique has been used. It has been possible to gather valuable information provided by researchers, technical experts in SDI, and teachers, experienced in using data from SDI. The results obtained with this technique make it possible to confirm that despite the interest of the SDI for the understanding of the territory, the use of SDI is still to come, since the tools that facilitate the path are still complex, as can be deduced from formulating the barriers that hinder its use.
\end{abstract}

Key words: Geography; territory-based learning; Spatial Data Infrastructures (SDI); Delphi Technique; geodata.

\title{
1 Introducción
}

El ingente incremento de datos georreferenciados, y por tanto de interés para la geografía, accesibles a la ciudadanía en general y al profesorado en particular, obliga a los docentes a plantearse cómo realizar un mejor aprovechamiento de los mismos, desde los niveles educativos de enseñanza secundaria. Bednarz y Van Der Schee (2006) basan su empleo en cuatro pilares: la formación del profesorado, disponer de software y de equipamiento adecuado, la existencia de una comunidad de aprendizaje que apoye al profesorado y su inclusión en el currículum de secundaria.

Este planteamiento refuerza la necesidad de formar al profesorado y al alumnado en el empleo de los datos abiertos y gratuitos (Rivas-Rebaque et al., 2019), cuya importancia temática y precisión temporal se completa con su ubicación en el territorio, surgiendo así el geodato (Lázaro, Izquierdo \& González, 2016) ofrecido por las IDE. Las IDE son: "un Sistema de Información Geográfica o SIG abierto implementado sobre la Red, con todo lo que ello conlleva: componentes distribuidos, interfaces estándares, interoperabilidad, coordinación, acceso a los datos, capacidad de análisis como objetivo" (Bernabé-Poveda \& López-Vázquez, 2012). Se alojan en un geoportal, al que se accede vía Internet. Sus características y prestaciones pueden variar de un país a otro (Vancauwenberghe et al., 2018). Ofrecen la ventaja de su calidad, interoperabilidad, transparencia, posibilidad de reutilización y la facilidad de acceso y actualización, a veces en 
tiempo real. Estos datos se ponen a disposición de la ciudadanía por los organismos públicos que los crean, impulsados por la Directiva INSPIRE de la UE (2007) y su política de datos abiertos, desarrollada por la ley sobre las infraestructuras y los servicios de información geográfica en España (LISIGE, 2010).

El potencial de la información geoespacial y su interés para la ciudadanía han sido señalados, no sólo como un tipo de información fundamental para la toma de decisiones y la gestión (MuroMedrano, 2012), sino como una vía para potenciar las smart cities o ciudades inteligentes (Roche, 2014) y también para el desenvolvimiento profesional (agricultura de precisión, arqueología, transporte, prospección de recursos naturales y estudios ambientales, entre otros muchos). El manejo de los datos adecuados refuerza un conocimiento territorial, fiable y preciso, que permite el desarrollo de la habilidad de explorar y visualizar el mundo real y sus problemas críticos (cambio climático, desastres naturales y su recuperación, para después responder a la conservación) (Tsou \& Yanow, 2010). Así, una sólida formación espacial, en la que los geodatos de las IDE sean un elemento esencial, facilitará a los estudiantes, futuros ciudadanos, el responder científicamente a cuestiones ambientales y sociales propias del siglo XXI.

Como punto de partida, se ha constatado que los geodatos de las IDE son generalmente desconocidos y muchas veces ignorados por docentes y estudiantes de geografía, lo que refuerza la importancia del trabajo que se presenta. El único contacto con las IDE se produce en algunos másteres en Tecnologías de la Información Geográfica (TIG) y en asignaturas sobre los Sistemas de la Información Geográfica (SIG), en algunos grados relacionados con la Geografía y la Ordenación del Territorio u otras ciencias del territorio, lo que tiene como consecuencia que apenas se utilicen en la enseñanza secundaria. De hecho, en las actas de los congresos de geografía y de didáctica de la geografía españolas de los últimos años en ningún caso se llegan a citar en más de un 10\% de las comunicaciones presentadas. Aunque a veces se emplean las IDE a través de distintas aplicaciones, el usuario no siempre es consciente de ello o no lo menciona de forma explícita.

Así, el desarrollo de las Infraestructuras de Datos Espaciales (IDE), propiciadas por la revolución tecnológica, ofrece una oportunidad, a través de su conocimiento y su empleo, para mejorar capacidades espaciales y digitales (Álvarez \& Lázaro, 2017), no sólo en la formación inicial del profesorado desde la universidad, que facilitaría su empleo en las aulas de secundaria, sino también en el profesorado universitario que forma a la ciudadanía impartiendo distintas materias relacionadas con el territorio.

Las IDE ofrecen un catálogo de datos referenciados en el territorio bajo la normativa y los servicios del Open Geospatial Consortium (OGC), empleando estándares que permiten el acceso a los datos mediante descarga directa o mediante una conexión a un servicio OGC (González \& Lázaro, 2011) 
Las descargas directas en local permiten la visualización de los datos utilizando algún Sistema de Información Geográfica. Esta visualización es también posible mediante la conexión a los servicios de datos OGC Web Map Service, abreviadamente WMS (el Catastro fue el primero en emplearlo) o el WMTS, que ofrece las mismas prestaciones, pero a través de teselas o tiles que al "partir en trozos" la cartografía aceleran su carga en los visualizadores. También integra servicios de descarga, que permiten, además de visualizar, bajar al ordenador en local datos vectoriales (Web Feature Service, WFS) y datos ráster (Web Coverage Service, WCS). Otros servicios permiten consultar catálogos de datos (Web Catalogue Service, CSW). El número de servicios ofrecidos en las IDE sigue creciendo e implementándose y su exhaustiva enumeración escapa al objetivo de estas páginas.

Los servicios IDE, por su propia naturaleza abierta, son accesibles a través de diversas vías y plataformas, como por ejemplo los visores del Instituto Geográfico Nacional (IGN), los globos virtuales y los SIG en la nube o SIGWebs.

A continuación vamos a exponer algunas iniciativas docentes que emplean las IDE, como antecedente al trabajo presentado. Abordaremos después la metodología empleada en la investigación sobre la utilidad de las IDE para aprender geografía, para seguir con la presentación de los resultados y una reflexión sobre los mismos en el apartado de recomendaciones y discusión para terminar con las conclusiones.

\section{Antecedentes: propuestas docentes que inician el empleo de las IDE}

En los últimos años se ha incrementado la investigación sobre la utilidad de las Tecnologías de la Información y la Comunicación (TIC) para aprender Geografía en la enseñanza secundaria, como se puede observar en la única revista española especializada en la enseñanza de la Geografía, Didáctica Geográfica, que de un 6 \% de artículos dedicados a las TIC (Sebastiá \& Tonda, 2011), pasa a un 15 \% (Tonda \& Sebastiá, 2013) dos años después. Además, existe un creciente número de trabajos fin de máster sobre el empleo de las TIC en la enseñanza de la geografía (Pérez Rendo, 2013; Sanchez Cabielles, 2014; Marco Dols, 2016 entre otros muchos) y diversas investigaciones aplicadas a la enseñanza secundaria buscando funcionalidades SIG en Google Earth (Patterson, 2007; Bonis Vázquez, 2015) empleando habilidades de indagación. En ninguno de estos casos se habla de la integración de las IDE y sus geodatos.

\subsection{Herramientas de uso generalizado por los docentes que posibilitan el empleo de las IDE}

Las IDE son una pequeña parte de las TIG (Nieto, 2016) y su empleo en el proceso de enseñanza y aprendizaje no es un hecho siempre consciente, ya que algunos visores ofrecen parte de los geodatos de los servicios IDE, sin necesidad de que el usuario tenga que establecer una conexión 
específica a los servicios OGC. Esta es la filosofía de la plataforma finlandesa PaikkaOppi (Houtsonen et al., 2014; Riihelä \& Mäki, 2015), diseñada para su empleo en las clases de Geografía en niveles no universitarios. Ofrece datos territoriales de Finlandia, fiables y periódicamente actualizados por el organismo responsable de los mismos. Además, prevé su uso en las pruebas de acceso a la universidad en los próximos años, con la finalidad de alcanzar un modelo docente en el que el estudiante sea capaz de comunicar lo que ha aprendido, más allá del tradicional examen.

Por otra parte, algunas de las IDE de las Comunidades Autónomas están integrando IDE didácticas, como es el caso de Aragón, que se ofrece cómo "la solución tecnológica desarrollada por el Instituto Geográfico de Aragón (IGEAR) que tiene como objetivo, difundir y promover el conocimiento del territorio aragonés así como el desarrollo de la competencia espacial del ciudadano" (https://idearagon.aragon.es/geojuegos/htm/es/index.html), y la IDE de Extremadura, con una parte destinada a escolares llamada IDE Didáctica (http://www.ideex.es/IDEDidacticaVisor/).

Los visualizadores del IGN (Iberpix, CartoCiudad o SignA), los globos virtuales (como Google Earth) u otros tipos de plataformas en la nube, como los SIG en la nube o SIGWeb, permiten una visualización directa de contenidos básicos que están en la base de datos IDE. A ellos se pueden añadir otras muchas capas de datos mediante la conexión a un servicio OGC, generalmente WMS y WMST; otros datos previamente descargados de las IDE y datos propios. Sin embargo, extendidas aplicaciones de Google no dan la opción de conectarse a los servicios OGC, a pesar de permitir integrar otros datos, como sucede con Google Maps o MyMaps, que sólo permite añadir datos desde determinados formatos de ficheros (CSV, de una hoja de cálculo o KML).

Otra opción empleada son los atlas de uso educativo, conectados a las IDE, y a otros sistemas, como el diseñado en Ucrania (Chabaniuk, \& Rudenko, 2019), que da continuidad a los trabajos en los Países Bajos de Aditya (2007) y Köbben, (2013), y el recientemente publicado en línea Atlas Nacional de España Interactivo (IGN, 2019).

Existen aplicaciones para dispositivos móviles que integran los servicios IDE de forma intuitiva y útil, diseñadas principalmente para el trabajo de campo como, por ejemplo, "Mapas de España" del IGN para Android, que emplea la tecnología Oruxmaps, con las funcionalidades de un terminal de GPS y además pone a disposición del usuario una valiosa cartografía, las imágenes aéreas del Plan Nacional de Ortoimágenes y la opción de añadir otras capas de información de las IDE a través de los servicios OGC. De ella se ha derivado la aplicación "Mapas de España Básicos", de manejo más sencillo, pensado para escolares. Otro ejemplo es la aplicación "Naturaleza MAPAMA", que ofrece los datos de la IDE del Banco de Datos para la Naturaleza poniendo a disposición de forma 
abierta y gratuita el Inventario Español del Patrimonio Natural y de la Biodiversidad, lo que permite trabajar en las aulas, por ejemplo, sobre las figuras de protección, su origen y su razón de ser.

Hemos visto que no todos los visores de mapas en la web cuentan con la opción de conectarse a un servicio OGC que permita el acceso a las bases de geodatos ofrecidos por las IDE. Y tampoco está garantizado que se empleen las IDE en el creciente uso de los Sistemas de Información Geográfica en las aulas de secundaria (Milson, Demirci \& Kerski, 2012; Del Campo et al., 2012).

\subsection{Experiencias docentes empleando las IDE}

Vamos a realizar un breve repaso de las iniciativas docentes que destacan por integrar las IDE en la enseñanza secundaria.

Una de las primeras iniciativas que surgen en torno a las IDE fue un curso de formación para el profesorado organizado e impartido por el IGN en los años de creación de la IDE de España (IDEE) y su geoportal. Sin embargo, no hubo muchos docentes sensibilizados con su integración en las aulas como un recurso educativo más.

La tesis doctoral de María Ester González (2012) ha sido una de las primeras en esta línea de investigación, en ella se expone la posibilidad de emplear las IDE con una técnica docente concreta, el aprendizaje basado en problemas (ABP). Argumenta su utilidad en base a las exigencias de mejora de las competencias TIC en el mundo educativo.

El Portal Educativo en Sistemas de Información Geográfica, PESIG (Boix \& Olivella, 2007) de Cataluña, que se presenta destinado a los docentes, integra, en algunas de sus actividades de formación, el empleo de las IDE, explicando pormenorizadamente cómo conectarse a un servicio WMS o WMST con la finalidad de visualizar imágenes. De este modo, se emplean los servicios IDE como un recurso más, sin que sea el elemento central de las actividades propuestas. Este proyecto busca un aprendizaje activo y significativo. El programa que se utiliza es gvSIG, software libre mayoritariamente empleado en el proyecto internacional Geo for all, que fomenta el uso del software libre en educación para el conocimiento territorial (geospatial education).

Posteriormente, las SIGWeb, están presentes en mayoría de las experiencias docentes, tanto en la enseñanza secundaria como en la formación de su profesorado. Podemos destacar el Atlas Digital Escolar (De Miguel et al., 2015, 2016) impulsado por la Universidad de Zaragoza empleando ArcGIS Online TM, Esri®, que en algunos mapas emplea los servicios OGC de visualización (WMS y WMST) integrados en la plataforma. Con los mapas elaborados se promueve la observación, el método indagatorio de aprendizaje y el aprendizaje por descubrimiento (Buzo, 2015). La misma herramienta SIGWeb la emplea el grupo de innovación educativa "Aprender con mapas", creado por los tres docentes de secundaria del Mapa Digital Escolar, que obtuvieron el XXXI Premio "Francisco Giner de los Ríos", Área de Humanidades y Ciencias Sociales, otorgado a 
esta metodología de trabajo (Buzo, 2016). La misma herramienta se emplea en algunas de las lessons plan del proyecto europeo Gl Learner (Zwartjes \& Lázaro, 2019, p. 51) y en el grupo de innovación e investigación docente de la Universidad Nacional de Educación a Distancia (MapsOnline) dirigido por la Dra. Lázaro, dedicado al profesorado universitario de geografía y otras ciencias territoriales y a la formación inicial de los docentes de secundaria.

La teoría del juego aplicada a la Geografía (Martínez Cebolla at al., 2017), emplea la IDE de Aragón. También las iniciativas de educación ambiental en Polonia (Pokojski et al., 2018), consideran imprescindibles las IDE para un mejor conocimiento del territorio.

Una opción escasamente explorada es el Sistema de Información Geográfica Nacional SignA, nodo natural de la Infraestructura de Datos Espaciales de España (IDEE), con el que se ha realizado una propuesta de actividades integradas en el curriculum (Lázaro, Álvarez \& González, 2016). El que no esté generalizado su empleo se puede explicar porque no ha sido diseñado específicamente para escolares, aunque cuenta con un creciente número de tutoriales volcados por el IGN en YouTube. Tampoco se usa en las aulas la conexión WMS de Google Earth, a pesar del gran número de propuestas de actividades geoespaciales para secundaria (Luque, 2011; López et al., 2013).

Ninguna de las iniciativas citadas se ocupa del horizonte futuro ni valora las barreras que dificultan la usabilidad de los geodatos de las IDE en la docencia. Entendiendo por usabilidad la facilidad de uso del producto en aspectos como consistencia o tiempo de respuesta (liménez, Yépez \& Vázquez, 2014).

\section{Objetivos y metodología}

Demostrar la potencialidad de los servicios IDE como recurso de datos geográficos primarios y de calidad, para su aprovechamiento en el proceso de enseñanza-aprendizaje, en la formación del profesorado y en las aulas de secundaria, es el objetivo principal de este trabajo. Con ello se pretende que el aprendizaje derivado de la interacción entre la nube y la realidad territorial facilite la creación de un pensamiento espacial crítico (Kerski, 2008; Cook et al., 2014) que debería conducir a incrementar la responsabilidad social sobre el territorio (Álvarez \& Lázaro, 2017).

Se ha considerado la técnica Delphi como la más adecuada por su facilidad para valorar el interés por un tema, en este caso la utilidad del empleo en la docencia de las IDE, tanto en la formación del profesorado como en los estudiantes de secundaria a los que se imparta docencia. Facilita realizar pronósticos definiendo escenarios futuros y seleccionar las variables de interés o ítems, entre otros muchos posibles resultados de investigación a obtener (Cabero \& Infante, 2014). Además, agiliza la consulta a expertos, en este caso conocedores y usuarios de las IDE, cualquiera 
que sea su lugar de residencia, haciendo viable el trabajo grupal por su flexibilidad de responder en cualquier momento y desde cualquier lugar.

\subsection{La técnica Delphi}

Se han seguido los parámetros metodológicos en los que López-Gómez (2018) resume la técnica: selección y conformación del panel de expertos (número de expertos y calidad del panel), proceso iterativo en rondas y criterios a considerar para la finalización del proceso cuando se llega a un consenso.

La técnica se inicia con la formulación de una o varias preguntas clave en formato abierto y cualitativo, que será la cuestión inicial sobre la que los expertos se deben pronunciar. A raíz de las respuestas obtenidas, la técnica permite elaborar rondas sucesivas de preguntas (retroalimentación controlada) (Gross, Hakim \& Weinblatt, 1983), en un formato cerrado, tipo cuestionario. Por lo que podemos afirmar que es una técnica que se inicia en formato cualitativo y termina en formato cuantitativo.

La independencia de las opiniones de cada uno de los expertos se garantiza por el anonimato entre ellos, el empleo del correo electrónico para la primera ronda, y los cuestionarios en los formularios de Google Drive para los ítems que se van reformulando a raíz de la retroalimentación recibida. Así, la respuesta estadística del grupo se obtiene a través de sus opiniones, argumentos y respuestas, sin la influencia de unos sobre otros, quedando reflejado su grado de acuerdo o desacuerdo (consenso) en los resultados finales de forma anónima (Landeta, 2002; Astigarraga, 2003).

\subsection{Selección y conformación del panel de expertos}

Se ha considerado esencial, para los resultados del trabajo, un perfil de informante conocedor y usuario de las IDE en una vertiente docente (formador del profesorado, profesor de universidad o de enseñanza secundaria) o en su desenvolvimiento profesional, es decir que empleara visores o servidores alimentados de sus servicios.

Un cuestionario pasado a más de un centenar de asistentes en varios cursos de formación de profesores de secundaria, pretendió ser la herramienta para la selección inicial de panelistas, pero ante el desconocimiento y la falta de preocupación en relación a las IDE de los mismos, fue necesario seleccionar expertos buscando evidencias de su empleo en su trayectoria profesional, docente e investigadora (publicaciones científicas, en ocasiones específicas para la formación del profesorado y cursos de formación impartidos) (Tabla 1). 
Tabla 1. Perfil profesional de los panelistas (todos ellos usuarios IDE)

\begin{tabular}{|l|c|}
\hline \multicolumn{1}{|c|}{ PERFIL DE INFORMANTE } & NÚMERO \\
\hline Docente de secundaria & 2 \\
\hline $\begin{array}{l}\text { Docente universidad, formador del profesorado de } \\
\text { secundaria }\end{array}$ & 3 \\
\hline Docente universidad & 8 \\
\hline Otros perfiles (investigador, técnico...) & 2 \\
\hline TOTAL & 15 \\
\hline
\end{tabular}

Fuente: elaboración propia

La literatura existente sobre la técnica Delphi considera, en función del objeto de investigación, una horquilla entre 10 y 15, 10 y 18 o entre 15 y 30 (López-Gómez, 2018, p. 23; Dimitrijević, 2012, p. 402; Ruiz Olabuénaga, 2012, p. 265) expertos por panel, considerando en éste a personas lo más cualificadas posible para el objeto de estudio. Por tanto una selección de 15, entre aquellos que cumpliendo las condiciones buscadas, accedieron a participar en el estudio hasta su finalización (se inició la primera ronda en marzo de 2017 y se terminó el proceso en diciembre del mismo año), se presenta como adecuada y suficiente. En ella, se ha procurado un perfil variado, tanto por el lugar de trabajo (10 informantes de España - 7 Madrid, 1 León, 1 Zaragoza y 1 Badajoz-, 2 América del Sur, y 1 Hungría), como por el abanico de edades y género (73\% varones y $26 \%$ mujeres). El encuestado más joven tenía al inicio de la primera ronda 26 años, y el mayor 70 años (Tabla 2).

Tabla 2. Edad y años de experiencia en IDE de los panelistas

\begin{tabular}{|l|c|c|c|c|c|c|}
\hline PERFIL PANELISTAS & MEDIA & MODA & MEDIANA & $\begin{array}{c}\text { DESVIACIÓN } \\
\text { TÍPICA }\end{array}$ & VALORMIN & $\begin{array}{c}\text { VALORM } \\
\text { AX }\end{array}$ \\
\hline Edad & 51,29 & - & 49,5 & 13,37 & 26 & 70 \\
\hline Trabajo en IDE & 12 & 15 & 15 & 4,74 & 1 & 15 \\
\hline
\end{tabular}

Fuente: elaboración propia

\subsection{Cuestiones iniciales abordadas y proceso iterativo de rondas}

Las preguntas iniciales tienen la finalidad de detectar la utilidad de las IDE en la enseñanza y aprendizaje de la geografía, las necesidades de formación del profesorado para su empleo en las aulas a partir de lo que los estudiantes deberían aprender y la metodología docente aconsejada 
para todo ello. Todas ellas son preguntas abiertas, dejando además una cuestión adicional para que sea posible añadir lo que los panelistas consideren oportuno. La formulación ha sido la siguiente: partiendo de la base de que usted conoce lo que es una Infraestructura de Datos Espaciales (IDE), estamos estudiando su utilidad en el aprendizaje de la geografía en las enseñanzas no universitarias (Enseñanza Secundaria): i. ¿Cree usted que son útiles para aprender Geografía? Argumente la respuesta; ii. ¿Qué formación deberían adquirir los estudiantes para apreciar/ integrar la potencialidad de las IDE en su aprendizaje?; iii. ¿Qué tipo de metodología docente puede ser la más adecuada para impulsar las IDE en las aulas?; iv. Otras observaciones, comentarios o recomendaciones que quiera hacernos llegar.

Los resultados obtenidos de la cuestión inicial planteada se exponen en el apartado de la primera ronda. Después se reformulan esos resultados en un formato de encuesta de respuesta cerrada en sus ítems (si, no y no sabe o no contesta por sus iniciales, ns/nc), si bien se deja la opción, en todas las cuestiones, de añadir información cualitativa. Para la cuestión relativa a las acciones formativas se solicita una jerarquización de las seis acciones aportadas en la ronda anterior. Las cuestiones de esta segunda ronda se plantean en cuatro secciones relacionadas con los resultados de la primera: y con los mismos títulos. i. utilidad de las IDE; ii. Formación que deberían adquirir los estudiantes para integrar la potencialidad de las IDE en su aprendizaje; iii. metodología docente para impulsar el empleo de las IDE en las aulas; iv. últimas cuestiones de recogida del consenso. Estos resultados se recogen en el apartado de la segunda ronda.

Dada la polarización en las respuestas obtenidas en la segunda ronda, no se ha considerado necesaria una tercera ronda, siguiendo las indicaciones de Astigarraga (2003):

aunque la formulación teórica del método Delphi propiamente dicho comprende varias etapas sucesivas de envíos de cuestionarios, de vaciado y de explotación, en buena parte de los casos puede limitarse a dos etapas, lo que sin embargo no afecta a la calidad de los resultados tal y como lo demuestra la experiencia acumulada en estudios similares.

\section{Resultados del proceso iterativo de rondas}

\subsection{Primera ronda}

Las respuestas de la primera ronda se resumen ratificando la argumentación, en algunas de ellas con las frases textuales de los panelistas.

a) Utilidad de las IDE

Se considera que las IDE son útiles en general, y también provechosas y beneficiosas para el aprendizaje de la geografía. Además, los datos de calidad (precisos y actualizados) que ofrecen se emplean frecuentemente en el desenvolvimiento profesional, facilitan la comprensión de conceptos 
geográficos y favorecen un conocimiento espacial que permite proponer soluciones a los problemas territoriales.

Las siguientes palabras textuales de los panelistas desarrollan la idea de su utilidad:

Permiten conocer el territorio y analizar diferentes temas desde un punto de vista espacial, entender comportamientos, sacar conclusiones y proponer soluciones a los problemas.

Los estudiantes necesitan saber que en su vida profesional deberán usar en muchos momentos datos geográficos, por ello, es relevante que se enseñen las IDE y su forma de manejo.

Sin duda, son muy útiles para aprender geografía. Los mapas son la principal herramienta del geógrafo, son la mejor forma de expresar los resultados de sus análisis, de las distribuciones y las relaciones de los fenómenos estudiados en el espacio. Las IDE ponen a disposición de los usuarios una ingente cantidad de mapas y de datos asociados a esos mapas. Poder usarlos, para enseñar y aprender geografía, es no ya útil, sino fundamental. La capacidad que tienen las IDE para hacer además atractiva la clase de geografía en las aulas, tanto de colegios como institutos, no puede ser desaprovechada.

Las Infraestructuras de Datos Espaciales, como el resto de Infraestructuras, están diseñadas y promovidas para facilitar a los usuarios el acceso a la información Geográfica (...) Partiendo de esta premisa, hoy es más sencillo encontrar, acceder y usar las fuentes de información geográfica disponibles. Además las organizaciones y agencias responsables de los datos están viendo la necesidad de avanzar en esta línea en un entorno cada vez más global y competitivo.

(Las IDE) ponen al servicio de los profesores las herramientas y los datos a través de los que se pueden explicar los conceptos teóricos de la disciplina. Los servicios de mapa (WMS, WFS, WCS o el catálogo de datos) proveen de información y de datos actualizados de calidad, que beneficia el aprendizaje de los alumnos y alumnas con datos de plena actualidad y calidad. Además, la interactividad que ofrecen estas plataformas, la posibilidad de descarga y manipulación de datos con software GIS (SIG), convierten a las IDE en herramientas fundamentales hoy en día para que el alumno aprenda de forma práctica. Ayudan a fijar los conceptos teóricos y por tanto, mejoran la calidad de la enseñanza.

El acceso a información geoespacial precisa y actualizada va a contribuir de forma significativa a una mejora de las tareas y proyectos de todos los profesionales 
relacionados con el territorio (geografía, topografía, ingeniería, urbanismo, medio ambiente, etc.). También va a permitir aumentar el nivel informativo de los ciudadanos sobre su territorio en el contexto de la nueva sociedad de la información digital.

Sin embargo, a pesar de la unanimidad existente en torno a la utilidad de las IDE en general y de que el 81,25\% de los panelistas están a favor de su empleo en las aulas de secundaria, el 18,75\% no ve la utilidad de las mismas como recurso educativo en niveles no universitarios tal y como se conciben y se ofrecen hoy en la Red. Por ello, consideran que su empleo se debe hacer en niveles educativos más avanzados y más relacionados con la profesión, lo que argumentan del siguiente modo:

(...) la usabilidad de los geoportales es muy mejorable y no me extraña que si alguien entra salga corriendo. Desde luego, el interfaz no está pensado para escolares.

Las IDE actualmente son utilizadas por grupos de usuarios muy específicos, que generalmente tienen relación directa con la información geográfica. La posibilidad de que las IDE sean utilizadas por usuarios sin formación en materia de información geográfica, es decir, por la ciudadanía en general resulta un objetivo muy ambicioso que requiere que los geoportales IDE cumplan los mínimos parámetros de usabilidad y sean rediseñados considerando los distintos perfiles de usuario (desde principiantes hasta expertos) que pueden hacer uso de las mismas.

Algunos panelistas, no sólo lo consideran una útil herramienta de aprendizaje, sino una fuente esencial de datos geográficos que un ciudadano del siglo XXI debería conocer:

(...) herramienta de aprendizaje para los alumnos, pero también objeto de estudio. En la era digital, los conocimientos espaciales son inherentes a la informática: es indispensable hacer ver a los alumnos la importancia de manejar correctamente las T.I.G. y los geodatos.

Uno de los profesores de secundaria argumenta que su utilización es fundamental no sólo para trabajar contenidos geográficos, sino también por la oportunidad de trabajar competencias y enumera todas y cada una de las acciones para adquirir las competencias recogidas en la legislación actual del currículum de secundaria empleando las IDE.

b) Formación que deberían adquirir los estudiantes para integrar la potencialidad de las IDE en su aprendizaje

Algunos de los panelistas centran la formación básica en los conceptos de cartografía digital y señalan como elementos a considerar: comprender cómo se estructura la información geográfica, manejar con soltura los sistemas de referencia, introducir las Tecnologías de la Información Geográfica (TIG) incluyendo qué es un Sistema de Información Geográfica (SIG) y diferenciar al 
menos un SIG de escritorio y un SIG en la nube. Así, es esencial el manejo de algún software, visor cartográfico o globo virtual que permita acceder a los datos de los servicios de las IDE. Con ellos se debería introducir al alumnado al conocimiento de los geodatos y a cuestiones como la calidad del dato y la fiabilidad de la IDE en la que se origina.

A esta formación esencial, se han añadido otros ítems considerados necesarios para que el estudiante sea capaz de crear cartografía digital e interactiva: aprender a seleccionar las capas que se quiere visualizar en su mapa; realizar operaciones básicas tales como asociar el zoom al cambio de escala, nortear el mapa, volver a centrar el mapa, etc.; aprender a diferenciar los tipos de IDE y seleccionar la información geográfica correcta; realizar los mapas con el empleo de las IDE como recurso para su creación, así como saber interpretarlos; conocer los componentes de una IDE (catálogo de metadatos, nomenclátor, visualizaciones de mapas, etc.) y saber que los servicios que ofrece están estandarizados para que cualquier programa o software sea compatible con los mismos; practicar y conocer el geoportal IDEE y los de la propia región, para familiarizarse con los visualizadores y los centros de descargas; valorar e incorporar las Infraestructuras de Datos Espaciales de España (IDEE) como un buscador de información geográfica al aprendizaje cotidiano, al igual que emplean, por ejemplo, la cartografía de Google.

c) Metodología docente para impulsar el empleo de las IDE en las aulas

Se habla de plantear casos prácticos para que sean resueltos por los estudiantes, empleando guiones de trabajo orientativos. Se considera que al ser una herramienta apenas empleada en secundaria hasta el momento, es importante que el profesorado se familiarice con ella previamente. Los métodos docentes que citan los panelistas son: el aprendizaje basado en proyectos, el trabajo de campo, el estudio de casos prácticos, el aprendizaje basado en problemas, el aprendizaje geográfico por descubrimiento basado en SIG (método inductivo), la gamificación, la combinación de teoría seguida de la correspondiente práctica en la clase o método demostrativo, el aprendizaje basado en mapas, la flipped classroom o clase invertida, los seminarios en el aula de informática y el método de investigación o de indagación. Todas estas estrategias pedagógicas tienen en común que responden a la metodología activa, que es la unánimemente defendida.

d) Otras observaciones, comentarios o recomendaciones aportadas

Curiosamente la mayoría consideran alguna actividad práctica para que el alumnado pruebe la usabilidad de las IDE, es decir que se invita a que se enfrenten a su empleo y a aprender haciendo o learning by doing, lo que Labouta y otros (2015) consideran la base del pensamiento científico de los discentes. Se aconseja realizar un recorrido por las IDE de todas las escalas (internacional, estatal, autonómica y local) y realizar alguna actividad con las mismas, y si alguna IDE dispone de apartado didáctico, como apuntan que sucede en la de Extremadura, que se aproveche el mismo y se valore. Se aporta el enlace al informe final del proyecto "Usabilidad de Geoportales IDE" 
(González, 2015), que "resume los resultados de la prueba de usabilidad realizada con 84 usuarios de 5 países que dejan en evidencia las dificultades que presenta el uso del geoportal IDE y en particular del visualizador de mapas"; y también nombres de instituciones y de docentes que están trabajando en este campo. Finalmente, se sistematizan las formas sugeridas de introducir las IDE en tres: i clase magistral; ii unidad didáctica orientada y dirigida por el profesor; iii método indagatorio siguiendo el modelo de Kerski (2011), que se inicia con el planteamiento de preguntas geográficas, se recoge información de diversas fuentes, que luego se organiza y analiza para responder a las preguntas y por último se actúa en consecuencia, con responsabilidad, aplicando el conocimiento adquirido.

Otros panelistas, alejados de la docencia en secundaria, hablan de la importancia de la voluntad política para impulsar su empleo:

Creo que es fundamental contar con un apoyo político fuerte para desarrollar estrategias de aprendizaje que utilicen las IDE, lo mismo que contar con técnicos motivados que lideren el proceso. Si la propia iniciativa IDE incluye líneas de acción en este sentido, mucho mejor (idealmente, acciones coordinadas entre las IDE y las Administraciones de Enseñanza). También contar con herramientas tecnológicas adaptadas a tales fines y accesibles a todas y todos sin restricciones de ningún tipo (como lo son las Tecnologías Libres de Información Geográfica-software geoespacial libre y abierto).

La riqueza en ítems aportados facilita el paso a la formulación de las cuestiones de la segunda ronda en formato de cuestionario cerrado.

\subsection{Segunda ronda}

Los resultados se exponen siguiendo los tres ejes temáticos anteriores: utilidad de las IDE; formación que deberían adquirir los estudiantes para integrar la potencialidad de las IDE en su aprendizaje; metodologías que favorezcan la integración de las IDE en las aulas. Para terminar con una pequeña recapitulación que aborda si el empleo de las IDE en secundaria se considera complejo, usable, útil y fácil (adjetivos más empleados en todo el proceso) y si mejora o no la calidad de la enseñanza.

a) Utilidad de las IDE

Las respuestas a las cuestiones formuladas con los resultados obtenidos en la ronda anterior se exponen a continuación.

En relación a si se utilizan las IDE de manera consciente en la vida cotidiana, existe una división de opiniones, cerca de la mitad de los panelistas considera que sí. Se matiza que la utilidad de su empleo está en función del perfil de usuario. Así, se considera que la utilidad mayor es para los profesionales relacionados con las ciencias del territorio y los investigadores, seguidos de cerca por 
los profesores universitarios (Figura 1), le siguen a mayor distancia el desempeño profesional en todos los niveles educativos, y la ciudadanía en general. Otros profesionales (no contemplados antes) serían los que menos utilidad encuentran a las IDE.

Figura 1. Utilidad del empleo de las IDE para los distintos grupos sociales

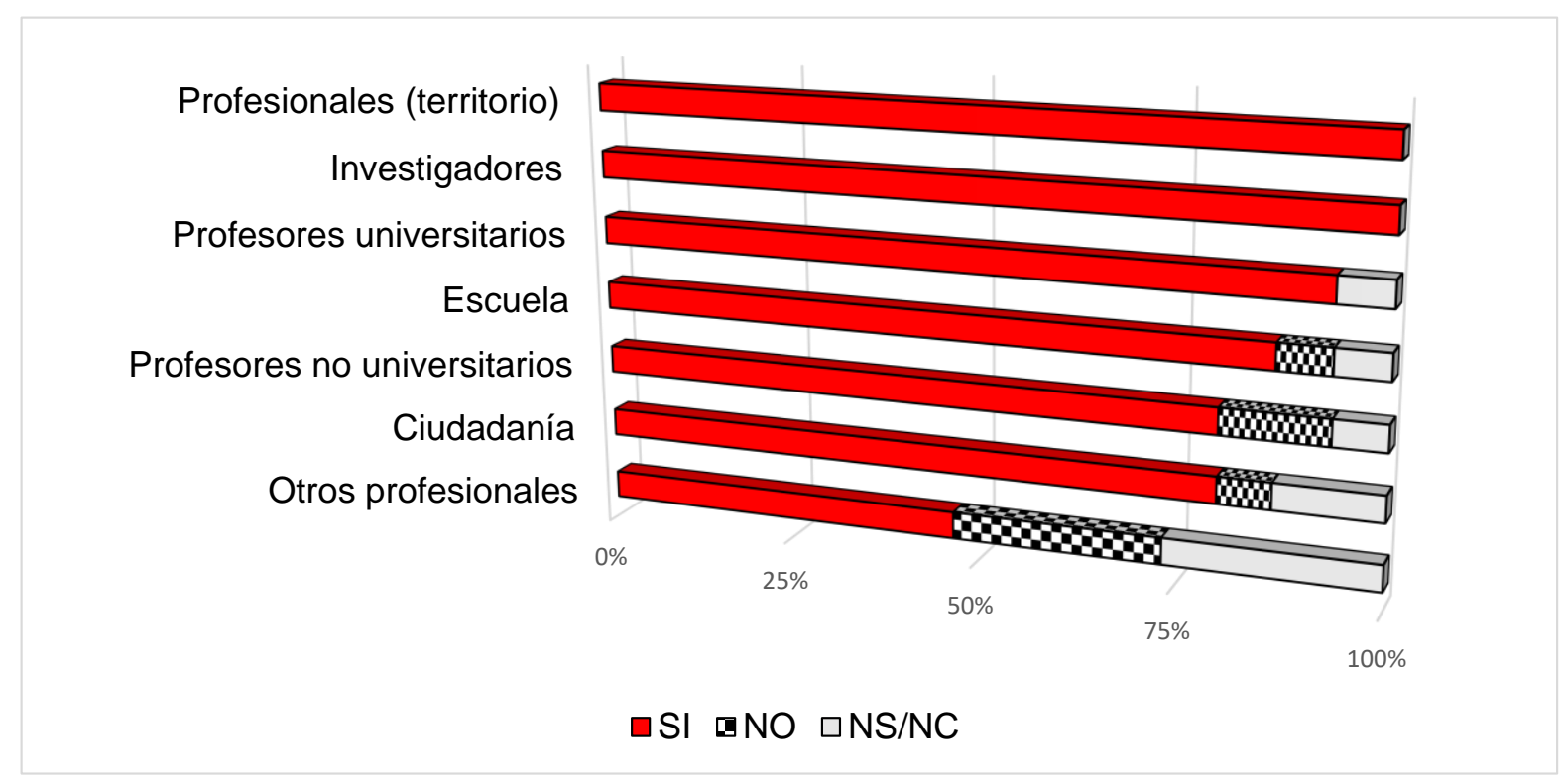

Fuente: elaboración propia

Después se abordan las cualidades de la IDE: utilidad, usabilidad, acceso sencillo y rápido, datos de calidad y gratuidad. Las respuestas muestran unanimidad sobre la utilidad general de las IDE y sobre los problemas de usabilidad. No es un aspecto fuerte de las IDE el acceso sencillo, intuitivo y rápido, lo que puede constituir una de las principales barreras en su empleo. En palabras de uno de los expertos:

En el estado actual de las IDE, en el que no es fácil añadir capas WMS no previstas por defecto, las IDE no son útiles para los no expertos. Es necesario desarrollar estrategias de usabilidad, ya sea a través de voz 'Añadir la capa de usos del suelo' o mediante estrategias en las que aparezcan nuevas capas predefinidas sin necesidad de incorporar la URL de la capa. Por esa razón mi respuesta ha sido ns/nc. En mi opinión hoy por hoy no son utilizables por usuarios no especializados y esa es la razón por la que se utiliza masivamente Google Maps y apenas se utilizan las IDE.

La calidad del dato y su gratuidad son cualidades destacadas por los panelistas. Queda de manifiesto que los organismos públicos, responsables de los datos, los actualizan periódicamente, filtrando y seleccionando aquellos publicables y gratuitos, sin infringir las leyes de seguridad y cumpliendo la normativa europea. 
Curiosamente, los panelistas en todo el proceso no emplean la palabra interoperabilidad, dan por hecho esta cualidad esencial de las IDE derivada de la estandarización de los datos.

b) Formación que deberían adquirir los estudiantes para integrar la potencialidad de las IDE en su aprendizaje

Se proponen dos afirmaciones para que los panelistas se definan sobre la interfaz: "los servicios WMS y los visores que emplean las IDE son muy adecuados para su empleo en secundaria" (el 66,7\% están de acuerdo, mientras que el 33,3\% no lo están) y "la interfaz de los servicios WMS y WFS no está pensada para escolares" (opiniones simétricamente divididas, un 46,6\% está de acuerdo y el mismo porcentaje no lo está). La mayoría está de acuerdo (80\%) en que "las IDE ayudarán al futuro profesional de los estudiantes", lo que refuerza su importancia en la formación del profesorado. Si bien un 20 \% no opinan así, de ellos un 6,7\% afirma que no ayudarán al futuro profesional de los estudiantes y un 13,3\% no responden a la cuestión, dejando así una puerta abierta a lo impredecible que puede ser el futuro.

Entre las categorías de formación para integrar las IDE en las aulas docentes consideradas en la ronda anterior, se acepta unánimemente la comprensión del territorio y sus problemas (Figura 2), que integra la esencia de la geografía y de las IDE. Le siguen en el consenso "estructurar la información geográfica"; "interpretar los datos de la IDE"; "geodatos y TIG" y "asimilar conceptos geográficos" (93,3\%). Y después, "acceso y selección de datos actualizados" (86,6 \% de los expertos), que consideramos como una de las mayores bondades de las IDE.

Los visores cartográficos y las acciones que se pueden realizar en estos visores (añadir capas, utilizar correctamente la escala del mapa, o manejar las herramientas básicas de los visores), como funciones y operaciones básicas, que deberían ser aprendidas por al alumnado, están considerados como un medio útil para integrar las IDE por el 86,6 \% de los expertos. Mientras que "realizar cartografía" se considera algo menos importante $(73,4 \%)$ en los niveles de enseñanza no universitaria, quizá porque hasta el siglo XXI no aparecen herramientas que permitan realizar cartografía de una forma sencilla e intuitiva, tales como los globos virtuales o las SIGWeb.

El empleo de un programa SIG de escritorio es otra categoría con divergencias entre los expertos (46,6\% lo califican como importante y otro 46,6\% creen que no). Hasta el momento los SIG de escritorio, por su complejidad, apenas se han empleado en secundaria salvo algunas adaptaciones para escolares en actividades muy concretas con software libre (QGIS o gvSIG).

El 53,4\% de los panelistas, entre ellos todos los docentes de secundaria, opinan que los SIG en la nube pueden ayudar a integrar las IDE en las aulas, mientras el $40 \%$ piensan que no. Por último, el nivel de calidad del dato en educación es considerado relevante por el $40 \%$ de los panelistas. 
Figura 2. Categorías para integrar las IDE en la formación de los estudiantes

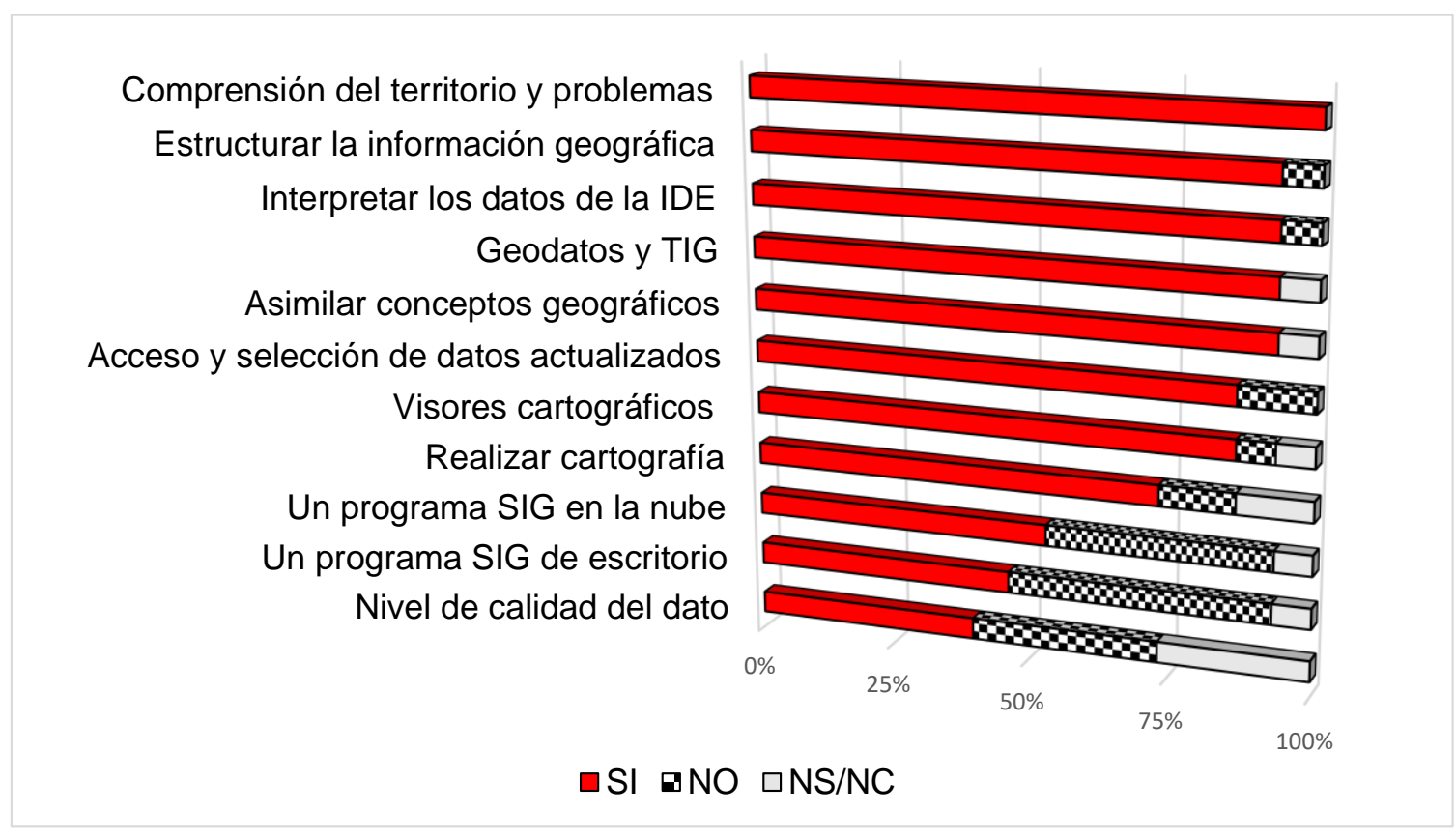

Fuente: elaboración propia

En resumen, las categorías de elementos más aceptados para integrar las IDE en la formación de los estudiantes de secundaria han sido las que hacen referencia a conceptos (asimilar conceptos geográficos, comprensión del territorio y sus problemas, geodatos y TIG). Le siguen las que hacen referencia a procedimientos (realizar cartografía, acceder y seleccionar la información con datos actualizados, interpretar los datos de la IDE y estructurar la información geográfica). Las categorías consideradas menos adecuadas son aquellas que tienen un grado mayor de complejidad, tanto tecnológica (programa de SIG de escritorio) como de abstracción (valoración del nivel de calidad del dato).

Por último, la formación en IDE como elemento transversal (Figura 3) es defendida por el 66,7\% de los panelistas, que considera necesario integrar su empleo de forma natural con la materia a impartir. Para ello aportan los contenidos básicos sobre IDE que consideran esenciales: adquirir conceptos básicos sobre las IDE (91,7\%), conocer el geoportal IDEE (83,3\%), familiarizarse con los centros de descargas (75\%), diferenciar distintos tipos de IDE y conocer los distintos componentes de una IDE. Algo más de la mitad consideran importante ampliar las opciones de conexión a los servicios IDE desde un dispositivo móvil (tableta, smartphone...) 
Figura 3. Contenidos básicos IDE como elemento transversal

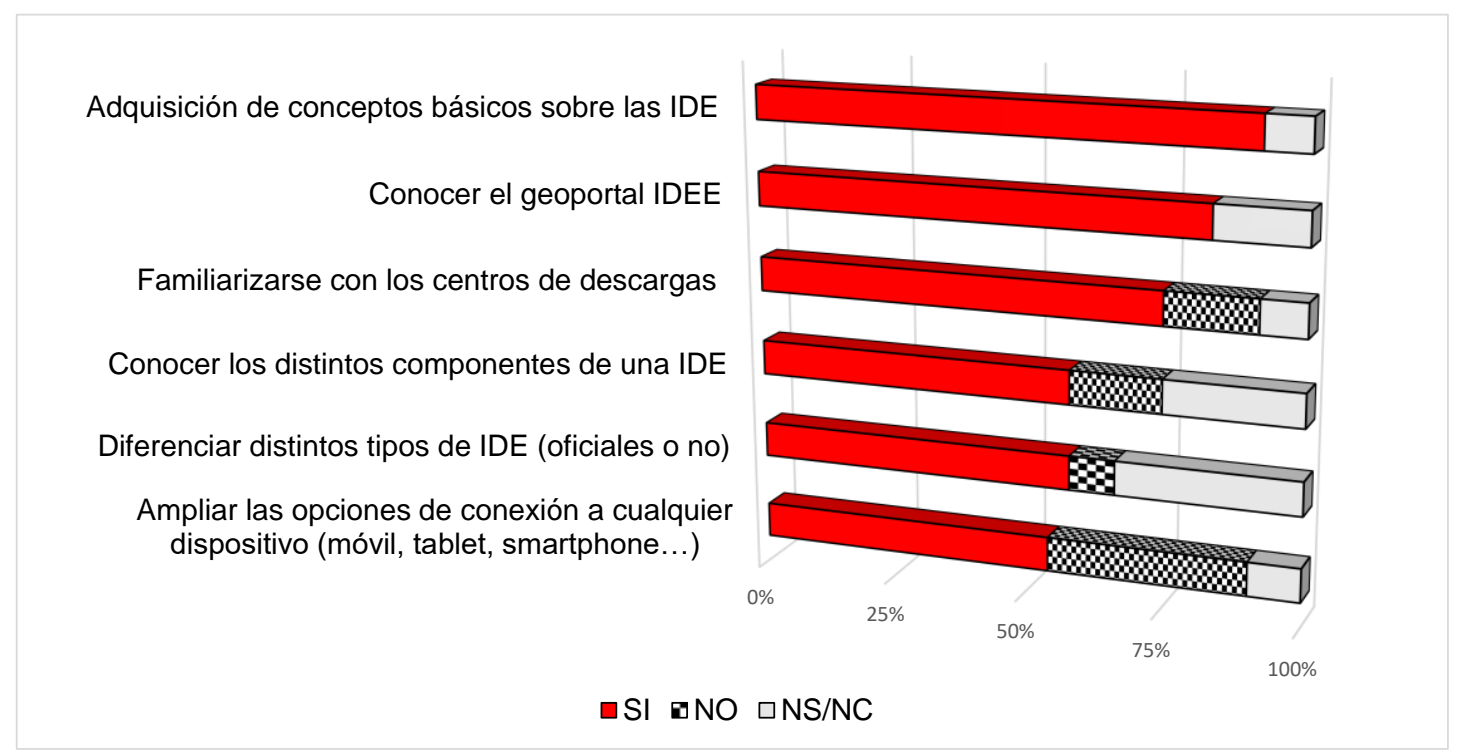

Fuente: elaboración propia

Un $20 \%$ de los panelistas no está de acuerdo en introducir conocimientos básicos sobre los servicios IDE como temas transversales en las aulas y un 13,3 \% no responde a esta cuestión, lo que nos permite afirmar que la tendencia en un futuro inmediato no será introducir de forma sistemática las IDE ni en la formación del profesorado ni en la enseñanza de la geografía.

c) Metodología docente para impulsar el empleo de las IDE en las aulas

La metodología activa se apunta como la más adecuada, por el 93,3\% de los panelistas, para integrar los servicios IDE en las aulas docentes, frente a la enseñanza tradicional centrada en las clases magistrales.

Se jerarquizan las estrategias docentes (Figura 4) sobresaliendo tres para integrar las IDE en el aula de secundaria: el aprendizaje basado en problemas, el aprendizaje basado en proyectos y los estudios de caso, que responden a una estrategia de indagación e investigación en la que es necesaria una búsqueda de datos. Basan el aprendizaje en el constructivismo, en la práctica del estudiante y en el trabajo colaborativo. Si bien en los estudios de caso, el trabajo se centra en resolver el caso, y no en lo que el estudiante aprenda, mientras que en el aprendizaje basado en problemas y en proyectos, el protagonismo lo tiene el estudiante y su proceso de aprendizaje. Todas estas estrategias facilitan el aprendizaje por descubrimiento, que es el que sigue en aceptación, con algún opositor, siendo el método inductivo el que lo define exigiendo al propio estudiante descubrir los conceptos y sus relaciones para integrarlos en su esquema cognitivo. Quizás por ello, no hay gran diferencia en la preferencia por éste y los tres anteriores. El argumento esgrimido por los panelistas en desacuerdo es que la mayoría de estas técnicas ralentizarían el ritmo de avance de la clase con unos programas curriculares muy exigentes en 
contenidos. La respuesta visibiliza que son los profesores de enseñanza secundaria los que encuentran inconvenientes en este tipo de enseñanza, más propia de una enseñanza personalizada con ratios profesor-alumno poco elevadas, que de la vida cotidiana en la mayoría de las aulas de secundaria.

La técnica menos aceptada es la moderna clase invertida o flipped classroom (46,6\%), lo que se podría explicar por el sobreesfuerzo que supone al profesorado la realización de vídeos didácticos con temas que integren las IDE, ya que hasta la fecha no hay material disponible sobre ello ni existe apoyo institucional en los centros para esta finalidad. Además, la competencia de elaborar vídeos, salvo en la enseñanza a distancia, no se contempla en la formación del profesorado universitario, lo que dificulta su aplicación al aula, especialmente en temas muy novedosos en los que apenas existen materiales.

Figura 4. Técnicas docentes para integrar el empleo de las IDE en el aula

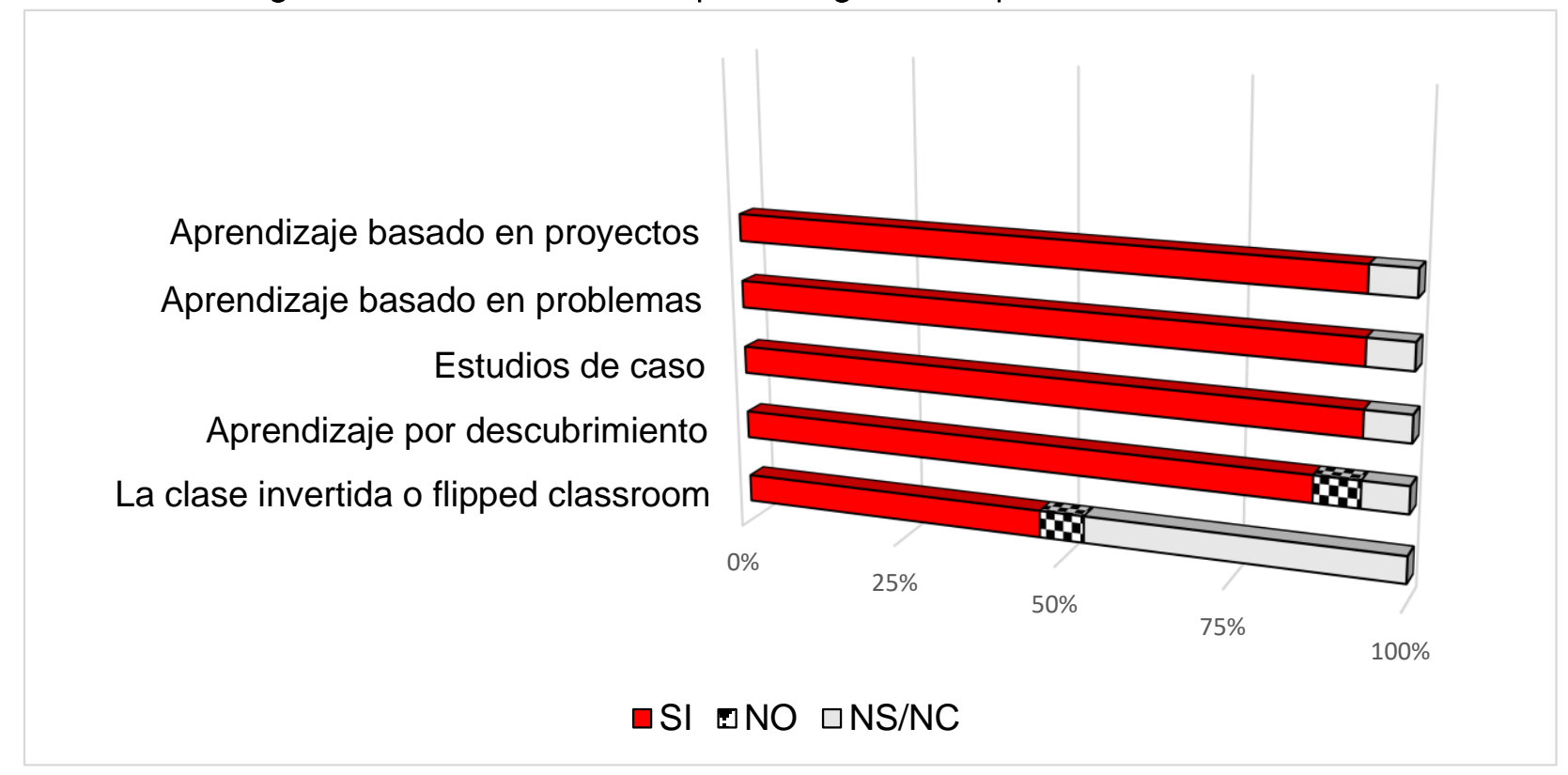

Fuente: elaboración propia

Las acciones formativas aportadas por los panelistas para integrar las IDE en la docencia, y por tanto necesarias en la formación del profesorado, es la única cuestión en la que ha sido necesario buscar una jerarquización para obtener consenso. Del 1 al 6, el 1 corresponde a la acción en el aula más adecuada para integrar los servicios de las IDE y adquirir un buen conocimiento territorial y el 6 corresponde a la acción menos adecuada para la misma finalidad. Así, las puntuaciones más altas serán las acciones formativas consideradas como las menos adecuadas para el aula.

El grado de consenso en cada una de las acciones formativas propuestas se ha calculado a partir de la media aritmética de las respuestas obtenidas, la moda, la mediana y la desviación típica (Tabla 3). Esta última muestra una escasa dispersión en las respuestas aportadas. Así mismo, se 
aporta el cuartil. Con estos datos, y a pesar de que en todas ellas no se ha eliminado el valor máximo y el mínimo, se observa que no hay grandes desacuerdos en las respuestas, quedando así claramente jerarquizadas las acciones docentes por orden de importancia.

Tabla 3. Acciones formativas sugeridas

\begin{tabular}{|l|c|c|c|c|c|c|}
\hline ACCIONES FORMATIVAS & MEDIA & MODA & $\begin{array}{l}\text { DESVIACIÓN } \\
\text { TÍPICA }\end{array}$ & Q1 & Q2 & Q3 \\
\hline $\begin{array}{l}\text { Los datos obtenidos de las IDE se } \\
\text { deben emplear contextualizados en el } \\
\text { tema correspondiente de la unidad } \\
\text { didáctica }\end{array}$ & 2,67 & 1 & 1,50 & 1 & 2 & 4 \\
\hline $\begin{array}{l}\text { Dividir la clase en una parte teórica y } \\
\text { luego aplicar la teoría explicada }\end{array}$ & 3,13 & 2 & 1,64 & 2 & 3 & 5 \\
\hline $\begin{array}{l}\text { Utilizar pequeñas herramientas que } \\
\text { faciliten el desarrollo de actividades de } \\
\text { aprendizaje basado en la } \\
\text { experimentación }\end{array}$ & 3,27 & 2 & 1,39 & 2 & 3 & 4 \\
\hline $\begin{array}{l}\text { Emplear las IDE en seminarios en las } \\
\text { aulas de informática }\end{array}$ & 3,27 & 5 & 1,49 & 2 & 3 & 5 \\
\hline $\begin{array}{l}\text { Integrar las IDE como competencia } \\
\text { transversal }\end{array}$ & 3,80 & 5 & 1,78 & 2 & 4 & 5 \\
\hline $\begin{array}{l}\text { Vincular el boom de Pokémon GO! a } \\
\text { los aspectos didácticos de las IDE }\end{array}$ & 4,87 & 6 & 1,85 & 4 & 6 & 6 \\
\hline
\end{tabular}

Fuente: elaboración propia

El que los datos obtenidos de las IDE se empleen en el contexto del tema al que se refieren se considera la cuestión principal, es decir, deben estar contextualizados en el tema correspondiente al de la unidad didáctica o tema a trabajar. Le sigue en importancia el dividir la clase en una parte teórica y luego aplicar la teoría explicada, siendo la segunda parte de la clase un ejemplo de lo visto en la primera a modo de pequeño laboratorio de experimentación. Es un método de enseñanza demostrativa muy extendido en la enseñanza de los Sistemas de Información Geográfica (Walsh 1992, U.S. Geological Survey 2005) y en la de otras herramientas informáticas.

Obtienen la misma puntuación o media aritmética el utilizar pequeñas herramientas que faciliten el desarrollo de actividades de aprendizaje basado en la experimentación y el formato de seminarios específicos en el aula de informática, si bien considerando la moda destaca la primera de ellas sobre la segunda. La consideración del conocimiento y empleo de los servicios IDE como competencia transversal no destaca entre las opciones posibles. Y la baja puntuación de la última acción sugerida indica que, a pesar de su potencial para la adquisición de competencias espaciales, el boom de Pokémon GO! ha sido una moda pasajera. 
d) Últimas cuestiones de recogida del consenso

Los cuatro adjetivos empleados para calificar el empleo de las IDE en las aulas de secundaria, por orden de importancia han sido: útil, usable, complejo y fácil. El consenso indica que de fácil tienen muy poco (Figura 5).

Figura 5. Adjetivos que califican el empleo de las IDE en las aulas de Secundaria

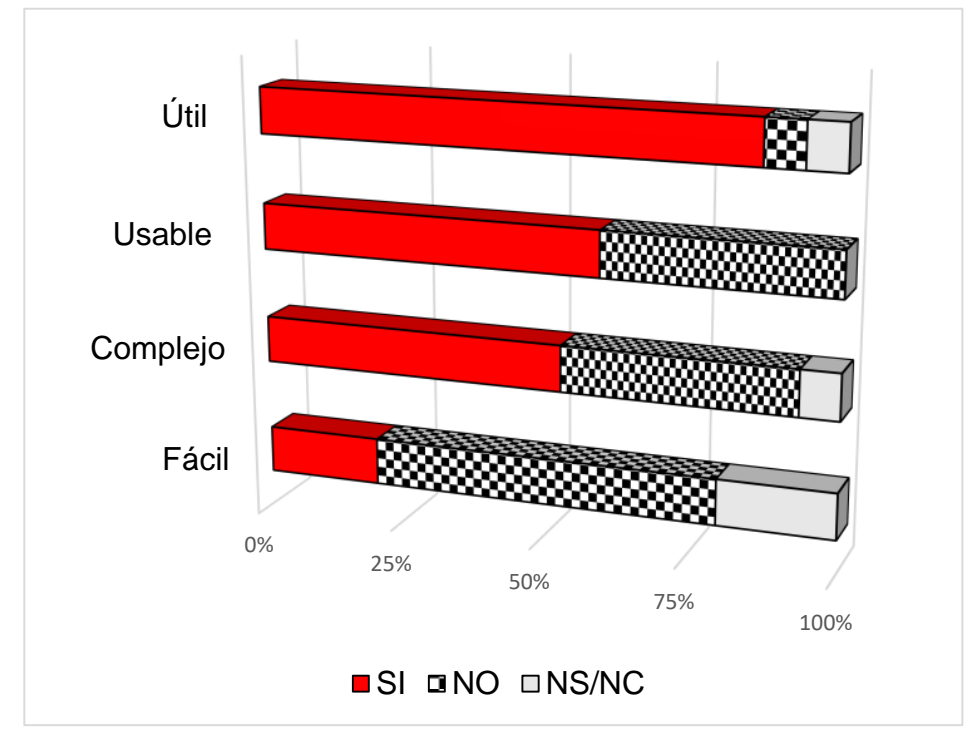

Fuente: elaboración propia

En relación a la pertinencia de las IDE, un $86,7 \%$ de expertos considera que su introducción en las aulas mejoraría la calidad de la enseñanza secundaria, mientras el 13,3\% no lo considera. Por tanto, parece aconsejable iniciar la formación al profesorado en relación con las IDE.

La clara definición de posturas excluye la posibilidad de una visión unilateral, pero manifiesta un consenso o acuerdo en la utilidad de las IDE como recurso docente, lo que ratifica la hipótesis fundamental del trabajo.

\section{Recomendaciones y discusión}

El método Delphi empleado en la investigación ha cubierto los objetivos esperados en ella, aportando una gran riqueza de datos que han hecho posible su análisis mostrando una realidad que permite vislumbrar su proyección a futuro, tal y como han realizado otros autores (MeletiouMavrotheris \& Koutsopoulos, 2018).

A pesar del consenso alcanzado en relación a la utilidad de las IDE para el aprendizaje de la geografía, pesan más las barreras en la usabilidad, que las ventajas en la utilidad de su empleo. Quizás en un futuro no muy lejano, el avance de la tecnología vaya resolviendo las barreras por superar (Benitez-Paez, 2018) y sea posible establecer un itinerario didáctico pedagógico para su empleo y difusión en las aulas como recurso docente integrando también las emergentes IDE 3D. 
A la vista de los resultados obtenidos, se ofrecen recomendaciones en cuatro líneas de acción, la primera en relación a la sociedad en general, la segunda en relación a la importancia de los datos, la tercera en relación a la búsqueda de itinerarios pedagógicos para la enseñanza secundaria y la cuarta en relación a la formación del profesorado, pieza clave para sentar la base de todo el proceso, y muy relacionada con el diseño curricular. Se parte de que los centros disponen de una conexión a Internet adecuada y suficiente, bien por cable en las aulas de informática o bien por wi-fi en la mayoría de los espacios del centro.

\subsection{En relación a la sociedad en general}

La sociedad española, con cerca de las tres cuartas partes de la población española entre 16 y 65 años conectada a diario a Internet y casi un $93 \%$ de los menores entre 10 y 15 años que también lo utiliza (INE, 2018), está preparada para sacar un mayor partido a los servicios IDE. Además, hay nichos de negocio que se basan en la geolocalización, lo que puede impulsar su empleo. Con él, se incentivaría la retroalimentación propia de la participación ciudadana y contribuiría a una mejor comprensión del territorio por parte de la ciudadanía.

Es fundamental contar con un apoyo político para desarrollar estrategias de aprendizaje que utilicen las IDE y contar con técnicos motivados que lideren el proceso de integración en la enseñanza secundaria y en la formación del profesorado. Si la propia iniciativa IDE incluye líneas de acción en este sentido, como sucede con la aparición de las IDE didácticas, será más sencillo el proceso. Se sugieren acciones coordinadas entre las IDE y las Administraciones de Enseñanza, la primera de las cuales debería producirse entre el IGN y el Instituto Nacional de Tecnologías Educativas y de Formación del Profesorado (INTEF).

\subsection{En relación a la importancia de los datos}

La formación en relación a los datos es necesaria, los panelistas así lo han ratificado, tanto en su tratamiento, como en los medios de adquirir, almacenar, visualizar, procesar, analizar, interpretar, y presentar los datos geográficos (Burrough \& McDonnell, 1998), lo que por extensión afecta a las TIG. Existe un creciente interés en aprender Geografía con datos reales y de primera mano, que las IDE aportan, lo que ayuda a construir el pensamiento crítico e impulsa el pensamiento espacial, ayudando a entender el territorio en el que se vive. Para esta misma finalidad Coetzee et al. (2017) proponen mejorar la funcionalidad de las IDE, y ampliarlas integrando datos de trabajos de tesis y proyectos que permitan realizar ejercicios docentes más variados, realistas y amplios. La Asociación Cartográfica Internacional (ICA), algunos institutos de investigación y algunas universidades están iniciando este camino.

Sin embargo, llama la atención que el nivel de calidad del dato no se considere relevante en educación. Quizás esto es un exponente más de su ausencia en la actual formación del profesorado, en la que tampoco se da importancia a las fake news o noticias falsas, que están en 
continuo crecimiento (Vosoughi, Roy \& Aral, 2018). Esta tendencia de carencia de formación y de preocupación por la calidad de los datos en los estudiantes, ha sido también constatada en el proyecto europeo Gl-Learner (Zwartjes et al., 2018, p. 22), dedicado a la integración de la ciencia de la geoinformación y los SIG en las aulas de secundaria (Donert et al., 2017; Zwartjes \& Lázaro, 2019).

Desde nuestro punto de vista, es necesario formar a los estudiantes no sólo en la búsqueda de información en distintas fuentes, sino también en aprender a discernir la calidad del dato, identificar los datos fiables según la fuente que los aporta y discriminarlos de los que no lo son. Este es uno de los pilares en los que se apoya el pensamiento crítico. El profesorado debe motivar y enseñar al estudiante a investigar la calidad del dato y a aprender a observar las inconsistencias en los mismos.

\subsection{En relación al impulso de ejemplos de aula e iniciativas en proceso}

Aunque los conceptos y procedimientos que las IDE permitirían adquirir se consideran de interés, las herramientas tecnológicas que facilitarían el camino resultan todavía complejas. De ahí las reticencias existentes por parte del profesorado, que no siempre ha recibido la necesaria e imprescindible formación inicial y permanente en este campo. Sin embargo, se ha demostrado que la utilidad del empleo de las IDE es el sentir unánime de muchos docentes que conocen su potencial, pero también lo es su complejidad. El empleo de las IDE a través de visores como Iberpix o CartoCiudad, globos virtuales como Google Earth (otras herramientas de Google no tienen funcionalidades que permitan integrar los geodatos que las IDE ofrecen) o las SIGWeb, de uso creciente (Buzo, 2019), están paliando los problemas de usabilidad.

Sería deseable un visualizador, alimentado de los datos de los servicios IDE, orientado a la educación, con algunos ejemplos para emplear directamente en el aula. El grupo de investigación educativa GEODIDAC, de la Universidad Complutense de Madrid, está desarrollando ejemplos de uso educativo con Iberpix4, demostrando con ello que es posible mejorar la comprensión del territorio a través de la observación directa, más allá del aprendizaje memorístico.

Se han diseñado y realizado algunas experiencias de aula con resultados satisfactorios relacionadas con los Objetivos de Desarrollo Sostenible (Álvarez \& Lázaro, 2018) y con el P.N. de las Tablas de Daimiel (Álvarez, Lázaro \& González, 2018) empleando la SIGWeb de ArcGIS Online, herramienta en continuo crecimiento (Kerski \& Baker, 2019) desde su aparición en 2012 y hoy impulsada por el programa gratuito para los centros escolares (http://colegios.esri.es/). Además, se están realizando pruebas de usabilidad de las IDE con alumnos de los distintos niveles educativos, tanto para ratificar las conclusiones del presente trabajo, como para obtener información que permita mejorar la usabilidad de las IDE, tal y como los panelistas han sugerido. 


\subsection{En relación a la formación del profesorado de secundaria}

La constatación del escaso conocimiento de las IDE por parte del profesorado de secundaria en general, hace que no sea un tema que preocupe a los docentes, y por tanto no se ha producido todavía la necesidad de una formación básica en IDE. Tampoco está generalizado el empleo de herramientas y visores de fácil usabilidad, que ofrecen los servicios IDE de forma predeterminada, sin intervención del usuario, como los ya citados.

Podemos afirmar que el profesorado es cada vez menos reticente y más receptivo a la tecnología existente, a la emergente y a la que está por llegar. Su aplicación al aula se puede ver potenciada por el marco de las competencias tecnológicas docentes impulsadas desde la Unión Europea (DIGCOMP, 2016; Comisión Europea, 2017; INTEF, 2017).

Una oportunidad en su integración está en los Másteres de Formación del Profesorado en los que se trabajan de forma prioritaria las fuentes de información geográfica. Un profesorado formado en IDE las integrará de forma natural en las aulas docentes como un recurso más, favoreciendo así métodos docentes activos y colaborativos, más allá de la tradicional enseñanza memorística con las técnicas de aprendizaje por proyectos, aprendizaje basado en problemas, estudios de caso y, con mayor dificultad, por las razones señaladas de escasez de tiempo, el aprendizaje por descubrimiento.

Quedan abiertas estas vías de trabajo en las aulas y de investigación docente acordes con las líneas de acción sugeridas.

\section{Conclusiones}

Los resultados de la aplicación de la técnica Delphi han permitido constatar que los panelistas coinciden en que la información que ofrecen las IDE (real, actualizada y accesible, desde cualquier lugar y en cualquier momento de forma gratuita), puede ayudar a una mejor comprensión de los temas territoriales por parte del estudiante. Así, se constata en este trabajo su potencialidad para la práctica docente, tanto en la enseñanza secundaria como en la formación del profesorado. Si bien se ha apuntado que para ello es necesario mejorar la usabilidad de la herramienta y que las barreras o dificultades que ahora mismo se presentan para los docentes se aligeren.

Un elemento esencial para un mejor aprovechamiento de las IDE es difundir el conocimiento de su potencial en los programas de formación del profesorado diseñando qué prioridades se deben considerar para facilitar su integración en los mismos. Es importante la voluntad política para impulsar su empleo en educación. El marco de la competencia digital docente podría ser su punto de partida.

Por tanto, se concluye que es necesario trabajar en dos direcciones, por una parte, en que las administraciones educativas y los responsables de las IDE dialoguen y avancen en una iniciativa que 
mejore su accesibilidad adaptándolas a las necesidades docentes, y por otra el profesorado debe recibir formación en el manejo de la información geoespacial en general y en las IDE en particular desde las universidades.

Los resultados obtenidos apuntan a unas previsiones futuras en el empleo de las IDE en las aulas de secundaria como un objetivo a largo plazo, a pesar del interés para la formación del profesorado y del alumnado, protagonista de la responsabilidad ciudadana en un futuro inmediato, y del hecho de que saber emplear geodatos primarios de calidad ayudaría a construir un pensamiento crítico, científico y técnico en nuestros jóvenes.

Agradecimientos: Agradecemos a todas las personas que han colaborado desinteresadamente con sus constructivas respuestas en las distintas rondas de la técnica Delphi, a los revisores de este artículo por sus acertadas sugerencias y a la Escuela de Doctorado de la Universidad Complutense de Madrid por su ayuda y motivación a la investigación presentada.

Declaración responsable: Las/os autoras/es declaran que no existe conflicto de interés con relación a la publicación de este artículo. Ambas/os autoras/es han diseñado el planteamiento del artículo, la introducción y los antecedentes. La principal contribución de cada autor/a se ha distribuido de la siguiente manera: Javier Álvarez ha realizado el trabajo de campo y redactado los resultados y conclusiones. María Luisa de Lázaro ha dirigido y revisado el trabajo. 


\section{Bibliografía}

Álvarez Otero, J., \& Lázaro y Torres, M.L. (2017). Spatial Data Infrastructures and Geography Learning. European Journal of Geography, 3(8), 19-29. Retrieved from http://www.eurogeographyjournal.eu/articles/2.Spatial\%20data\%20infrastructures\%20and\%20G eography\%20learning.pdf

Álvarez-Otero, J., \& de Lázaro y Torres, M.L. (2018) Education in Sustainable Development Goals Using the Spatial Data Infrastructures and the TPACK Model. Education Sciences, 8(4), 171. https://doi.org/10.3390/educsci8040171

Álvarez Otero, J., Lázaro Torres, M.L.de, \& González González, M.J. (2018). A cloud-based GIScience learning approach to Spanish National Parks. European Journal of Geography, 9(2), 620. Retrieved from

http://www.eurogeographyjournal.eu/articles/01f.\%20revised.Alvarez_LazaroyGonzalez_Spanish P_N1_vr9_abstract_changed_sub3.pdf

Aditya, T. (2007). The national atlas as a metaphor for improved use of a national geospatial data infrastructure (Doctoral dissertation, Utrecht University, Netherlands). Retrieved from https://dspace.library.uu.nl/handle/1874/21785

Astigarraga, E. (2003). El método Delphi. San Sebastián: Universidad de Deusto.

Bednarz, S., \& Van der Schee, J. (2006). Europe and the United States: the implementation of geographic information systems in secondary education in two contexts, Journal of Technology, Pedagogy and Education, 15(2), 191-205. https://doi.org/10.1080/14759390600769573

Benitez-Paez, F., Degbelo, A., Trilles, S., \& Huerta, J. (2018). Roadblocks hindering the reuse of open geodata in Colombia and Spain: A data user's perspective. ISPRS International Journal of Geo-Information, 7(1), 6. https://doi.org/10.3390/ijgi7010006

Bernabé-Poveda, M.A., \& López-Vázquez, C.M. (2012). Fundamentos de las Infraestructuras de Datos Espaciales. Madrid: UPM-Press, Serie Científica.

Boix, G., \& Olivella, R., (2007). Los Sistemas de Información Geográfica (SIG) aplicados a la educación. El proyecto PESIG (Portal Educativo en SIG). In M. J. Marrón Gaite, J. Salom Carrasco, \& X. M. Souto González, Las competencias geográficas para la educación ciudadana (pp. 2332). Valencia: Universidad de Valencia. Retrieved from: http://www.sigte.udg.edu/pesig/uploads/images/projecte/comunicacion_completa_SIGTE.pdf Bonis Vázquez, Á. (2015). El uso de las TIC y de Google Earth como contribución a la interiorización de los contenidos en geografía (Master's dissertation, Universidad de Navarra, Spain). 
Burrough, P., \& McDonnell, R. (1998). Principles of geographical information systems. Oxford: Oxford University Press.

Buzo, I. (2015). Aplicación de la metodología del aprendizaje geográfico por descubrimiento basado en SIG en proyectos didácticos para $2^{\circ}$ de Bachillerato. In R. Sebastiá, \& E. M. Tonda (Eds). La investigación y la innovación en la enseñanza de la geografía (pp. 477-489). Alicante: Universidad de Alicante.

Buzo, I. (Coord) (2016). Las SIGWebs en la Geografía de Secundaria para la mejora del pensamiento espacial (Memoria presentada para la obtención del XXXI Premio "Francisco Giner de los Ríos" Área de Humanidades y Ciencias Sociales") (BOE 17 mayo 2016) (Unpublished).

Buzo, I. (in press). El ecosistema de aplicaciones de ArcGIS Online utilizados en la enseñanza de la geografía. In Nuevos desafíos en la educación geográfica (Preprint del texto presentado al IX Congreso Ibérico de Didáctica de la Geografía, Santiago de Compostela).

Cabero, J., \& Infante, A. (2014). Empleo del método Delphi y su empleo en la investigación en Comunicación y Educación. EDUTEC Revista Electrónica de Investigación Educativa, 48, 1-16. Retrieved from http://edutec.rediris.es/Revelec2/Revelec48/pdf/Edutece_n48_CaberoInfante.pdf

Chabaniuk, V., \& Rudenko, L. (2019). Relational Geospatial Technologies: Background Theory, Practical Example and Needs in Education. In de Miguel, R., Donert, K., \& Koutsopoulos, K. (Eds) Geospatial Technologies in Geography Education (EUROGEO Book Series) (pp. 63-83). Cham: Springer. hittps://doi.org/10.1007/978-3-030-17783-6_4

Coetzee, S., Steiniger, S., Köbben, B., Iwaniak, A., Kaczmarek, I., ... Moellering, H. (2017). The Academic SDI - Towards understanding spatial data infrastructures for research and education. In M. Peters (Ed.), Advances in Cartography and GIScience. ICACl 2017. Lecture Notes in Geoinformation and Cartography (pp. 99-113). Cham: Springer. https://doi.org/10.1007/9783-319-57336-6_8

Cook, C.N., Inayatullah, S., Burgman, M.A., Sutherland, W.J., \& Wintle, B.A. (2014). Strategic foresight: how planning for the unpredictable can improve environmental decision-making. Trends in ecology \& evolution, 29(9), 531-541. https://doi.org/10.1016/j.tree.2014.07.005

Comisión Europea (2017). Digital Transformation Scoreboard. Retrieved from http://ec.europa.eu/growth/content/digital-transformation-scoreboard-2017-0_en Digital scoreboard reports retrieved from https://ec.europa.eu/digital-single-market/en/downloadscoreboard-reports

Del Campo, A., Romera, C., Capdevila, J., Nieto, J. A., \& de Lázaro, M. L. (2012). Spain: Institutional initiatives for improving geography teaching with GIS. In A. J. Milson, A. Demirci \& J. J. 
Kerski (Eds.), International perspectives on teaching and learning with GIS in secondary schools (pp. 243-253). Dordrecht: Springer.

De Miguel González, R., Lázaro y Torres, M.L., Velilla Gil, J., Buzo Sánchez, I., \& Guallart, C. (2015). Atlas Digital Escolar: aprender Geografía con ArcGIS Online. In Sebastiá, R. y Tonda, E.M. (Eds). La investigación y la innovación en la enseñanza de la geografía (pp. 925-936). Alicante: Universidad de Alicante.

De Miguel González, R., Lázaro y Torres, M.L., Velilla Gil, J., Buzo Sánchez, I., \& Guallart, C. (2016). Atlas Digital Escolar: Internet, geografía y educación. Ar@cne. Revista Electrónica de Recursos de Internet sobre Geografía y Ciencias Sociales, 212, Retrieved from http://www.ub.edu/geocrit/aracne/aracne-212.pdf

DIGCOMP (2016). A Framework for Developing and Understanding Digital Competence in Europe. Retrieved from https://ec.europa.eu/jrc/en/publication/eur-scientific-and-technical-researchreports/digcomp-20-digital-competence-framework-citizens-update-phase-1-conceptual-reference-

$\underline{\text { model }}$

Dimitrijević, B., Simic, V., Radonjic, V., \& Kostic-Ljubisavljevic, A. (2012). The Delphi method as a research tool: an application in transportation and logistics systems evaluations. The 6th International Quality Conference. Center for Quality, Faculty of Engineering, University of Kragujevac (Serbia). https://doi.org/10.13140/RG.2.1.1798.6646

Donert, K., Desmidt, F., Lázaro, M.L. de, González, R., Lindner-Fally, M., Parkinson, A., Prodan, D., Woloszynska-Wisniewska, E., \& Zwartjes, L. (2016). The GI-Learner Approach. GI_Forum Journal for Geographic Information Science, 2, 134-146, https://doi.org/10.1553/giscience2016_02_s134

González, M.E. (2012). Las Infraestructuras de Datos Espaciales (IDE) como un recurso educativo TIC. Estrategias de formación y difusión para el profesorado de la Educación Secundaria Obligatoria (Doctoral dissertation, Universidad Politécnica de Madrid, Spain). Retrieved from http://oa.upm.es/11015/

González, M.E. (2015). Informe final del proyecto Usabilidad de Geoportales IDE Retrieved from http://comisiones.ipgh.org/CARTOGRAFIA/PAT2015.html

González, M.J., \& Lázaro, M.L. de (2011) La geoinformación y su importancia para las tecnologías de la información geográfica. Ar@cne, 148. Retrieved from http://www.ub.es/geocrit/aracne/aracne-148.htm.

Gross, M., Hakim, S., \& Weinblatt, J. (1983). Evaluation of alternative arterial roads: A modified Delphi approach. Environments, 1(15), 27-38. 
Houtsonen, L., Mäki, S., Riihelä, J., Toivonen, T., \& Tulivuori, J. (2014). Paikkaoppi: a Web based learning environment for Finnish Schools. In R. de Miguel Gonzalez \& K. Donert (Eds.), Innovative Learning Geography in Europe: New Challenges for the 21st Century (pp. 89-100). Newcastle upon Tyne: Cambridge Scholars Publishing.

IGN (2019). Atlas Nacional de España Interactivo. Retrieved from https://interactivoatlasnacional.ign.es/\#c=home

Instituto Nacional de Estadística (2018). Encuesta sobre Equipamiento y Uso de Tecnologías de Información y Comunicación en los Hogares. Retrieved from https://www.ine.es/prensa/tich_2018.pdf

INTEF (2017). Marco Común de Competencia Digital Docente - Septiembre 2017. Retrieved from https://aprende.intef.es/sites/default/files/2018-05/2017_1020_Marco-Com\%C3\%BAn-de-

\section{Competencia-Digital-Docente.pdf}

Jiménez Calderón, L., Yépez Campoverde, J., \& Vázquez Hoehne, A. (2014). El usuario como factor de éxito en el diseño de un geoportal. GeoFocus Revista Internacional de Ciencia y Tecnología de la Información Geográfica, 14, 181-210. Retrieved from http://geofocus.rediris.es/2014/Articulo10_2014.pdf

Kerski, J.J. (2008). Developing Spatial Thinking Skills in Education and Society. ArcWatch. Retrieved from http://www.esri.com/news/arcwatch/0108/spatial-thinking.html

Kerski, J.J. (2011). Sleepwalking into the Future - The Case for Spatial Analysis Throughout Education. In T. Jekel, A. Koller, K. Donert \& R. Vogler (Eds.), Learning with Gl 2011 (pp. 2-11). Berlin/Offenbach: Herbert Wichmann Verlag, VDE VERLAG GMBH.

Kerski J.J., \& Baker T.R. (2019) Infusing Educational Practice with Web GIS. In R. de Miguel, K. Donert \& K. Koutsopoulos (Eds.), Geospatial Technologies in Geography Education. Key Challenges in Geography (EUROGEO Book Series) (pp. 3-19). Cham: Springer. https://doi.org/10.1007/978-3-030-17783-6_1

Köbben, B. (2013). Towards a national atlas of the Netherlands as part of the national spatial data infrastructure. The Cartographic Journal, 50(3), 225-231.

https://doi.org/10.1179/1743277413Y.0000000056

Labouta, H.I., Kenny, N.A.; Li, R., Anikovskiy, M., Reid, L., \& Cramb, D.T. (2018). Learning science by doing science: an authentic science process learning model in postsecondary education, International Journal of Science Education, 40(12), 1476-1492. https://doi.org/10.1080/09500693.2018.1484966 
Landeta, J. (2002). El método Delphi: una técnica de previsión para la incertidumbre. Barcelona: Ariel.

Lázaro y Torres, M.L. de, Álvarez Otero, J., \& González González, M.J. (2016). Aprender Geografía de España empleando SignA. In R. Sebastiá \& E. M. Tonda (Eds.), La investigación y la innovación en la enseñanza de la geografía (pp. 25-39). Alicante: Universidad de Alicante.

Lázaro, M.L.de, Izquierdo, S., \& González, M.J. (2016). Geodatos y paisaje: De la nube al aula universitaria. Boletín de la Asociación de Geógrafos Españoles, 70, 371-391. https://doi.org/10.21138/bage.2175

López-Gómez, E. (2018). El método Delphi en la investigación actual en Educación: una revisión teórica y metodológica. Educación XXI, 1(21), 17-40. https://doi.org/10.5944/educXX1.15536 López, A. A., Escolano, C. L., Solé, C. S., Antón, M. Z., Llovería, R. M., \& Campos, Á. P. (2013). El potencial de Google Earth aplicado al análisis espacial en geografía. In R. de Miguel González, M. L. de Lázaro Torres \& M. J. Marrón Gaite, Innovación en la enseñanza de la geografía ante los desafíos sociales y territoriales (pp. 179-194). Zaragoza: Institución Fernando el Católico-CSIC.

Luque, R. M. (2011). El uso de la cartografía y la imagen digital como recurso didáctico en la enseñanza secundaria. Algunas precisiones en torno a Google Earth. Boletín de la Asociación de Geógrafos Españoles, 55, 183-210. Retrieved from: https://www.agegeografia.es/ojs/index.php/bage/article/viewFile/1318/1241

Marco Dols, P. (2016). Los Sistemas de Información Geográfica: otra forma de impartir la Geografía en Secundaria (Master's Thesis, Universidad Jaume I, Spain). Retrieved from https://core.ac.uk/download/pdf/61494865.pdf

Martínez Cebolla, E., Gómez Cabello, F., \& López Martín, F. (2017). Aprendiendo Geografía con una IDE didáctica. Los geojuegos de IDE ARAGÓN. Revista Mapping, 26(182), 26-36. Retrieved from

http://revistamapping.com/wp-content/uploads/2017/09/Revista-MAPPING-182.pdf\#page=28

Meletiou-Mavrotheris, M., \& Koutsopoulos, K. (2018). Projecting the Future of Cloud Computing in Education: A foresight study using the Delphi Method. In K. C. Koutsopoulos, K. Doukas \& Y. Kotsanis (Eds.), Handbook of Research on Educational Design and Cloud Computing in Modern Classroom Settings (pp. 262-290). IGl Global. https://doi.org/10.4018/978-1-5225-30534.. h012

Milson, A. J., Demirci, A., \& Kerski, J. J. (Eds.) (2012). International Perspectives on Teaching and Learning with GIS in Secondary Schools. New York: Springer. 
Muro-Medrano, P. (2012). Etapas de la popularización de las infraestructuras de información geoespacial. GeoFocus, Revista Internacional de Ciencia y Tecnología de la Información Geográfica 12, 1-5. Retrieved from: http://geofocus.rediris.es/2012/Editorial_2012.pdf

Nieto Barbero, G. (2016). Análisis de la práctica educativa con SIG en la enseñanza de la geografía de la educación secundaria. Un estudio de caso en Baden-Württemberg, Alemania (Doctoral dissertation, Universidad de Barcelona, Spain). Retrieved from http://bit.ly/2Gab/YM

Patterson, T.D. (2007). Google Earth as a (Not Just) Geography Education Tool. Journal of Geography, 106(4), 145-152, https://doi.org/10.1080/00221340701678032

Pérez-Rendo, M. (2013). Tecnologías de Información Geográfica como herramienta educativa: Análisis y Perspectiva (Master's Thesis, Universidad Internacional de La Rioja, Spain). Retrieved from http://bit.ly/2YMiosu

Pokojski, W., Angiel, J., \& Pokojska, P. (2018). Importance of digital spatial data in environmental education. Edukacja Biologiczna i Środowiskowa, 1, 34-38.

https://doi.org/10.24131/3247.180105

Riihelä, J., \& Mäki, S. (2015). Designing and implementing an online GIS tool for schools: The Finnish case of the PaikkaOppi project. Journal of Geography, 114(1), 15-25.

https://doi.org/10.1080/00221341.2014.897362

Rivas-Rebaque, B.; Gértrudix-Barrio, F., \& de Cisneros de Britto, J.C. (2019). La percepción del docente universitario ante el uso y valor de los datos abiertos. Educación XX1, 22(2), 141-163. https://doi.org/10.5944/educXX1.21317

Roche, S. (2014). Geographic Information Science I: Why does a smart city need to be spatially enabled? Progress in Human Geography 38(5), 703-711.

https://doi.org/10.1177/0309132513517365

Ruiz Olabuénaga, J. I. (2012). Metodología de la investigación cualitativa (5th ed.). Universidad de Deusto.

Sánchez Cabielles, P. (2014). TIC y didáctica de la Geografía: el papel del SIG en la Educación Secundaria (Master's Thesis, Universidad de Cantabria, Spain). Retrieved from http://bit.ly/2JuybOh

Sebastiá, R., \& Tonda, E. M. (2011). Características y evolución de la Revista Didáctica Geográfica. Didáctica Geográfica 12, 19-48. Retrieved from hitp://www.agegeografia.es/didacticageografica/index.php/didacticageografica/article/view/57

Tonda-Monllor, E. M., \& Sebastiá-Alcaraz, R. (2013). Producción científica en la Didáctica de la Geografía Urbana: los congresos españoles, los congresos ibéricos y la revista Didáctica 
Geográfica (Segunda Época). In W.AA., A Cidade, um laboratório para a educação geográfica (pp.65-78). Lisbon: Universidade de Oporto y Asociación de Profesores de Didáctica de la Geografía (AGE). Retrieved from https://www.agegeografia.es/didacticageografia/docs/Publicaciones/2013_ebook.pdf

Tsou, M.H., \& Yanow, K. (2010). Enhancing General Education with Geographic Information Science and Spatial Literacy., URISA Journal 22(2), 45-55. Retrieved from https://geoinfo.sdsu.edu/hightech/Images/URISAjournal/2010-Tsou-YanowURISA\%20Journal\%20Vol.22\%20lssue\%202.pdf

U.S. Geological Survey (USGS) (2005). Geographic Information Systems in Education, U.S.: Department of the Interior.

Vancauwenberghe, G., Valečkaitè, K., van Loenen, B., \& Welle Donker, F. (2018). Assessing the Openness of Spatial Data Infrastructures (SDI): Towards a Map of Open SDI. International Journal of Spatial Data Infrastructures Research, 13, 88-100. https://doi.org/10.2902/1725$\underline{0463.2018 .13 . a r t 9}$

Vosoughi, S., Roy, D., \& Aral, S. (2018). The spread of true and false news online. Science, 359(6380), 1146-1151. https://doi.org/10.1126/science.aap9559

Walsh, S. (1992). Spatial education and integrated hands-on training: Essential foundations of GIS instruction. Journal of Geography, 44(2), 54-61.

https://doi.org/10.1080/00221349208979079

Zwartjes, L., Lázaro, M.L. de, Desmidt, F. Donert, K, Álvarez, J. ... \& Prodan, D. (2018). La necesidad de integrar el pensamiento espacial en educación. Gl Learner. Creando una línea de aprendizaje basada en el pensamiento espacial. Retrieved from http://www.gilearner.ugent.be/wp-content/uploads/GI-Learner-O7_ES. pdf

Zwartjes, L., \& Lázaro Torres, M.L. de (2019). Geospatial Thinking Learning Lines in Secondary Education: The GI Learner Project. In R. de Miguel, K. Donert \& K. Koutsopoulos (Eds.), Geospatial Technologies in Geography Education. Key Challenges in Geography (EUROGEO Book Series) (pp. 41-61). Cham: Springer. htips://doi.org/10.1007/978-3-030-17783-6_3 